\title{
Continuous Positive Airway Pressure Impairs Renal Function in Newborn Goats
}

\author{
JAMES E. FEWELL, AND J. B. NORTON, JR. \\ Departments of Pediatrics and Physiologv. University of Arkansas for Medical Sciences, Little Rock. Arkansas, USA
}

\begin{abstract}
Summary
Continuous positive airway pressure (CPAP) is used routinely to improve oxygenation in newborns who have intrapulmonary shunts and hypoxemia that is refractory to usual oxygen therapy. Although the cardiovascular and pulmonary effects of CPAP on newborns are well known, little information is available concerning the effect of CPAP on renal function. Therefore, we determined the effect of CPAP $\left(7.5 \mathrm{~cm} \mathrm{H}_{2} \mathrm{O}\right)$ on urine flow, sodium excretion, and glomerular filtration rate in six newborn goats that were lightly anesthetized with methoxyflurane. CPAP decreased urine flow, sodium excretion, and glomerular filtration rate. CPAP also decreased pulse pressure but did not change mean systemic arterial pressure or heart rate. We conclude that CPAP can impair renal function in newborns without significantly altering renal perfusion pressure.
\end{abstract}

\section{Speculation}

Newborns have a decreased glomerular filtration rate and a decreased ability to excrete sodium loads. Continuous positive airway pressure may further impair renal function in newborns who have the respiratory distress syndrome.

Continuous positive airway pressure (CPAP) was introduced by Gregory et al. (7) as part of the management of the neonatal respiratory distress syndrome. CPAP is now used routinely to improve oxygenation in newborns who have intrapulmonary shunts and hypoxemia that is refractory to usual oxygen therapy. Although the effects of CPAP on the cardiovascular and pulmonary systems are well known $(2,5,16,19,22)$, little information is available concerning the effect of CPAP on renal function. Two studies have demonstrated that increasing airway pressure alters renal hemodynamics in newborns $(5,14)$.

Gabriele et al. (5) demonstrated that CPAP $(11 \mathrm{~mm} \mathrm{Hg})$ decreases cardiac output and renal blood flow in newborn lambs. Furthermore, Moore et al. (14) demonstrated that intermittent positive pressure ventilation reverses the normal distribution of renal cortical blood flow in 3- to 5-day-old monkeys. Although these studies demonstrate that increasing airway pressure during all or part of the ventilatory cycle alters renal hemodynamics, they do not provide other essential information about renal function.

The purpose of this study, then, was to further define the effects of CPAP on renal function in newborns. Specifically, we determined urine flow, glomerular filtration rate, and sodium excretion during CPAP in newborn goats.

\section{MATERIALS AND METHODS}

Six newborn goats ( 8 to 17 days old) were lightly anesthetized by inhalation of methoxyflurane. Each goat was placed supine. and its trachea was intubated with a cuffed endotracheal tube. The cuff was inflated to a gas-tight fit, and the tube was connected to an open-circuit anesthesia system (continuous gas flow rate, 6 liters/min; 0.5 to $1.0 \%$ methoxyfluane in $30 \%$ oxygen). A rig catheter was placed in line with the endotracheal tube for conti uous monitoring of proximal airway pressure. A polyethyle catheter was inserted into a femoral artery and advanced to $t$ ascending aorta for measurement of mean systemic arterial prt sure, pulse pressure, and heart rate. A femoral vein was cannulat for administration of fluids. The ureters were cannulated wi polyethylene tubing for measurement of urine flow.

Each experiment consisted of six consecutive 30-min perior two 30-min control periods during which airway pressure w atmospheric; two 30-min experimental periods during which a way pressure was increased to $7.5 \mathrm{~cm} \mathrm{H}_{2} \mathrm{O}$ (CPAP); and two 3 min recovery periods during which airway pressure was atmc pheric. The experimental protocol began when urine flow 1 mained stable $( \pm 10 \%)$ for two consecutive 30 -min periods. $\mathrm{CP} /$ was applied by tightening a screw clamp on the orifice of anesthesia bag incorporated into the expiratory limb of the ane thesia circuit. Body temperature, measured rectally, was mai tained at $37^{\circ} \mathrm{C}$ by an external heating pad.

Pulmonary, cardiovascular, and renal variables were measur during each of the control, experimental, and recovery perior The pulmonary variables, arterial $\mathrm{PO}_{2}, \mathrm{PCO}_{2}$, and $\mathrm{pH}$, we measured at the midpoint of the second $30-\mathrm{min}$ period of ea condition. and the cardiovascular variables, heart rate. me systemic arterial pressure, and pulse pressure, were measured the midpoint of each 30 -min period. The pressures were measur by a Statham P23Db strain gauge manometer and recorded on Electronics for Medicine DR-8 optical recorder.

Glomerular filtration rate was estimated from the clearance inulin. Throughout each experiment, a solution of inulin (3. $\mathrm{mg} / \mathrm{ml}$ in $0.45 \%$ sodium chloride) was infused IV at a rate of 0 . $\mathrm{ml} / \mathrm{kg} / \mathrm{min}$ to maintain plasma inulin at $0.25 \mathrm{mg} / \mathrm{ml}$. F measurements of renal variables, urine was collected at the end each $30-\mathrm{min}$ period, and a $3 \mathrm{ml}$ blood sample was drawn at $\mathrm{t}$ midpoint of each of these periods. The volume of blood withdrai was replaced by an equal volume of $6 \%$ dextran in $0.9 \%$ sodiu chloride in which the red blood cells from the previous collecti period were resuspended. Urine flow and plasma and urine co centrations of sodium and inulin (8) were measured, and th sodium excretion, glomerular filtration rate, and fractional rea sorption of sodium were calculated. In addition, plasma and uri osmolality were measured, and osmolal clearance and free wal clearance were calculated.

To analyze the data statistically, we performed a one-w analysis of variance for repeated measurements of the same va able to determine if there was a significant $(P<0.05)$ differen between any of the periods (21). If there was a significant diff ence, we then performed a Dunnett's multiple range $t$ test determine which means were statistically different $(P<0.05)$ frc the mean of the control periods (20).

\section{RESULTS}

Urine flow, sodium excretion, and glomerular filtration rate decreased in response to CPAP $\left(7.5 \mathrm{~cm} \mathrm{\textrm {H } _ { 2 } \mathrm { O }}\right.$ ) (Table 1). Osmo 
POSITIVE AIRWAY PRESSURE

Table 1. Effect of CPAP on renal variables in newborn goats ${ }^{1}$

\begin{tabular}{|c|c|c|c|c|c|}
\hline Airway pressure (min) & $\begin{array}{c}\text { Urine flow ( } \mathrm{ml} / \mathrm{min} / \\
\mathrm{kg} \text { ) }\end{array}$ & $\begin{array}{l}\text { Sodium excretion } \\
(\mu \mathrm{Eq} / \mathrm{min} / \mathrm{kg})\end{array}$ & $\begin{array}{l}\text { Glomerular filtration } \\
\text { rate }(\mathrm{ml} / \mathrm{min} / \mathrm{kg})\end{array}$ & $\begin{array}{l}\text { Osmolal clearance } \\
(\mathrm{ml} / \mathrm{min} / \mathrm{kg})\end{array}$ & $\begin{array}{l}\text { Free-water clearance } \\
(\mathrm{ml} / \mathrm{min} / \mathrm{kg})\end{array}$ \\
\hline \multicolumn{6}{|l|}{ Control (atmospheric) } \\
\hline $0-30$ & $0.023 \pm 0.002^{2}$ & $0.380 \pm 0.054$ & $2.00 \pm 0.29$ & $0.039 \pm 0.009$ & $-0.016 \pm 0.001$ \\
\hline $30-60$ & $0.022 \pm 0.002$ & $0.409 \pm 0.034$ & $1.81 \pm 0.34$ & $0.039 \pm 0.012$ & $-0.017 \pm 0.012$ \\
\hline \multicolumn{6}{|l|}{ CPAP $\left(7.5 \mathrm{~cm} \mathrm{H}{ }_{2} \mathrm{O}\right)$} \\
\hline $60-90$ & $0.012 \pm 0.003^{3}$ & $0.208 \pm 0.037^{3}$ & $0.90 \pm 0.27^{3}$ & $0.024 \pm 0.018$ & $-0.012 \pm 0.012$ \\
\hline $90-120$ & $0.011 \pm 0.003$ & $0.231 \pm 0.076^{3}$ & $1.22 \pm 0.40^{3}$ & $0.018 \pm 0.013^{3}$ & $-0.001 \pm 0.007$ \\
\hline \multicolumn{6}{|l|}{ Recovery (atmospheric) } \\
\hline $120-150$ & $0.024 \pm 0.003$ & $0.449 \pm 0.084$ & $2.12 \pm 0.49$ & $0.032 \pm 0.011$ & $-0.008 \pm 0.007$ \\
\hline $150-180$ & $0.024 \pm 0.002$ & $0.509 \pm 0.143$ & $1.74 \pm 0.17$ & $0.038 \pm 0.007$ & $-0.008 \pm 0.008$ \\
\hline
\end{tabular}

${ }^{\prime} n=6$.

2 Mean \pm 1 S.D

Significant difference at the 0.05 level of significance from the mean of the control periods.

Table 2. Effect of CPAP on cardiovascular variables in newborn

\begin{tabular}{lccc} 
Airway pressure (min) & $\begin{array}{c}\text { goats } \\
\text { Heart rate } \\
\text { (beats/min) }\end{array}$ & $\begin{array}{c}\text { Mean arterial } \\
\text { pressure }(\mathrm{mm} \\
\mathrm{Hg})\end{array}$ & $\begin{array}{c}\text { Pulse } \\
\text { pressure } \\
(\mathrm{mm} \mathrm{Hg})\end{array}$ \\
\hline $\begin{array}{l}\text { Control (atmospheric) } \\
15\end{array}$ & $166 \pm 8^{2}$ & $59 \pm 2$ & $45 \pm 1$ \\
45 & $161 \pm 9$ & $57 \pm 3$ & $45 \pm 1$ \\
CPAP (7.5 cm H2O) & & & \\
75 & $163 \pm 6$ & $57 \pm 2$ & $41 \pm 2^{3}$ \\
105 & $161 \pm 7$ & $58 \pm 3$ & $41 \pm 2^{3}$
\end{tabular}

Recovery (atmospheric)

\begin{tabular}{lrrr}
135 & $157 \pm 7$ & $56 \pm 2$ & $45 \pm 2$ \\
165 & $157 \pm 8$ & $56 \pm 3$ & $44 \pm 3$ \\
\hline
\end{tabular}

$n=6$

2 Mean \pm IS.D.

"Significant difference at the 0.05 level of significance from the mean of the control periods.

clearance also decreased, but free water clearance did not change significantly (Table 1). Fractional reabsorption of sodium remained constant $(98.8 \%)$.

Pulse pressure also decreased, but heart rate and mean systemic arterial pressure were unchanged (Table 2).

Arterial blood gases and $\mathrm{pH}$ did not change significantly (Table 3).

\section{DISCUSSION}

This study demonstrates that CPAP can impair renal function in newborn goats. Specifically, CPAP $\left(7.5 \mathrm{~cm} \mathrm{H}_{2} \mathrm{O}\right)$ decreased urine flow, sodium excretion, and glomerular filtration rate.

This study was performed on newborn goats that did not have significant pulmonary disease, and one might anticipate that their hemodynamic response to CPAP would be greater than that of newborns who have the respiratory distress syndrome and decreased lung compliance. However, a similar cardiovascular response, decreased pulse pressure and unchanged heart rate and mean systemic arterial pressure, has been reported in newborns with the respiratory distress syndrome during treatment with CPAP ( 9.0 to $27.1 \mathrm{~cm} \mathrm{H}_{2} \mathrm{O}$ ) $(2,7)$. Thus, CPAP may also impair renal function in newborns with the respiratory distress syndrome.

Although this study was not designed to determine the mechanism of the renal response to CPAP, our findings allow us to rule out certain possibilities and speculate upon the mechanism. Three possible mechanisms are changes in renal perfusion pressure, changes in circulating hormones, and changes in renal sympathetic nervous activity. Changes in renal perfusion pressure can be ruled
Table 3. Lack of effect of CPAP on pulmonary variables in

\begin{tabular}{|c|c|c|c|}
\hline $\begin{array}{l}\text { Atmospheric pressure } \\
(\min )\end{array}$ & $\mathrm{pH}$ & $\mathrm{PaO}_{2}(\mathrm{~mm} \mathrm{Hg})$ & $\begin{array}{c}\mathrm{PaCO}_{2} \\
(\mathrm{~mm} \mathrm{Hg})\end{array}$ \\
\hline \multicolumn{4}{|l|}{$\begin{array}{l}\text { Control (atmos- } \\
\text { pheric) }\end{array}$} \\
\hline $45^{r}$ & $7.29 \pm 0.06^{2}$ & $78.9 \pm 24.6$ & $42.3 \pm 11.4$ \\
\hline $\mathrm{CPAP}\left(7.5 \mathrm{~cm} \mathrm{H} \mathrm{H}_{2} \mathrm{O}\right)$ & & & \\
\hline 105 & $7.31 \pm 0.06$ & $85.7 \pm 22.9$ & $39.9 \pm 6.2$ \\
\hline
\end{tabular}

Recovery (atmospheric)

165
$\begin{aligned} & 1 \\ & n=6.37 \pm 0.11\end{aligned} \quad 88.8 \pm 23.7$
2 Mean \pm I S.D.

out because this variable did not change significantly in our study, as indicated by unchanged mean systemic arterial pressure (Table 2 ). Although much emphasis has been placed on changes in circulating concentrations of antidiuretic hormone during increased airway pressure in both infants (14) and adults $(6,18)$, antidiuretic hormone also seems unlikely to be the mechanism of the renal response to CPAP because free water clearance did not decrease in our study (Table 1).

Others have suggested that changes in renal function during increased airway pressure are predominantly caused by changes in renal hemodynamics rather than by changes primarily related to antidiuretic hormone (12). Renal hemodynamic changes during CPAP may be caused by alterations in renal sympathetic nervous activity. In support of this is the finding that renal denervation eliminates the renal response to continuous positive-pressure ventilation (CPPV) in dogs (4). In this study, the renal responses of the intact right kidney and the denervated left kidney were compared during CPPV. CPPV decreased urine flow, sodium excretion, effective renal plasma flow, and the glomerular filtration rate in the intact right kidney but did not change these variables in the denervated left kidney. Inasmuch as both kidneys were exposed to the same hormones, antidiuretic hormone seems unlikely to have played a role in the renal response. Rather, these findings suggest that impaired renal function during CPPV is secondary to increased renal sympathetic nervous activity.

Renal sympathetic nervous activity can be affected by changes in the arterial carbon dioxide tension (15), by activation of cardiopulmonary receptors (9), and by changes in the activity of carotid sinus and aortic arch baroreceptors $(10,11)$. Changes in carbon dioxide tension seem unlikely to be responsible for increased renal sympathetic nervous activity during CPAP because carbon dioxide tension did not change significantly in our study (Table 3). Activation of cardiopulmonary baroreceptors which have vagal affer- 
ents also seems unlikely to be responsible. Previous experiments have shown that bilateral cervical vagotomy does not alter the cardiovascular $(13,17)$ or the renal $(1,3)$ response to increased airway pressure. However, because denervation of the aortic arch and carotid sinus baroreceptors eliminates the renal response to CPPV (3), changes in the activity of the carotid sinus and aortic arch baroreceptors during CPAP may well increase renal sympathetic nervous activity.

Thus, we suggest that increased airway pressure decreases cardiac output, which, in turn decreases carotid sinus and aortic arch baroreceptor activity. Integration of these nerve signals from the arterial baroreceptors by the central nervous system results in increased renal sympathetic nervous activity, and this increases renal vascular resistance and decreases glomerular filtration rate. The decrease in urine flow and sodium excretion appears to result from the decreased glomerular filtration rate.

\section{REFERENCES AND NOTES}

1. Baratz. R. A.. Philbin D. M., and Patterson. R. W.: Plasma antidiuretic hormone and urinary output during continuous positive pressure breathing in dogs. Anesthesiology, 34: 510 (1971).

2. Corbet. A. J. S., Ross, J. A., Beaudry, P. H., Stern. L.: Effects of positive pressure breathing on aADN, in hyaline membrane disease. J. Appl. Physiol.. 38: 33 (1975).

3. Fewell. J. E., and Bond. (i. C.: Role of sinoaortic baroreceptors in mediating the renal response to continuous positive-pressure ventilation in the dog. Physiologist. 20: 29 (1977).

4. Fewell. J. E.. and Bond. (i. C.: Renal denervation eliminates the renal response to continuous positive-pressure ventilation. Proc. Soc. Exp. Biol. Med.. 161: $574(1979)$.

5. Ciabriele. (;.. Rosenfeld. C. R.. Fixler. D. E... and Wheeler. J. M.: Continuous airway pressure breathing with the headbox in the newborn lamb: effects on regional hlood flows. Pediatrics. 54: 858 (1977).

6. Ciauer, O. H., Henry. J. P., and Sieker, H. O.: Cardiac receptors and fluid volume control. Prog (ardiovasc. Dis., 4: 1 (1961).

7. Gregory. G. A.. Kitterman. J. A.. Phibbs. R. H.. Tooley. W. H., and Hamilton. W. K.: Treatment of the idiopathic respiratory distress syndrome with contin. uous positive airway pressure. N. Engl. J. Med.. 284: 1333 (1971).
8 . Heyrovsky. A.: A new method for the determination of inulin in plasma and urine. Clin. Chim. Acta. l: 470 (1956).

9. Karim. F.. Kidd. C.. Malpus, C. M., and Penna. P. E.: The effects of stimulation of the left atrial receptors on sympathetic efferent nerve activity. J. Physiol. 227: $243(1972)$.

10. Katz. M. A.. and Shear, L.: Effect of renal nerves on renal hemodynamics. I. Direct stimulation and carotid occlusion. Nephron. 14: 246 (1975).

11. Kezdi. P.. and Geller. F.: Baroreceptor control of postganglionic sympathetic nerve discharge. Am. J. Physiol.. 2/4: 427 (196x).

12. Kumar. A.. Pontoppidan. H.. Baratz. R. A.. and Laver. M. B.: Inappropriate response to increased plasma $A D H$ during mechanical ventilation in acute respiratory failure. Anesthesiology, 40: $215(1974)$.

13. Maulsby, R. L., and Hoff. H. F.: Hypotensive mechanisms of pulmonary insufflation in dogs. Am. J. Physiol. 20): 505 (1962).

14. Moore. E. S.. Galvez. M. B., Paton. J. B.. Fisher. D. E.. and Behrman. R. E. Effects of positive ventilation on intrarenal blood how in infant primates. Pediatr. Res.. \&: 792 (1974)

15. Norman. J. N.. Maclntvre. J.. Shearer. J. R.. Craigen. I. M.. and Smith. (j.. Eflect of carbon dioxide on renal blood how. Am. J. Physiol.. 214: 672 (1970).

16. Powers, W. F.. Swyer. P. R.: The peripheral hemodynamic effects of continuous positive transpulmonary pressure breathing in neonates free from cardiorespiratory disease. Pediatrics, 50: 203 (1975)

17. Scharf. S. M.. (aldini. P.. and Ingram. R. H., Jr.: Cardiovascular effects of increasing airway pressure in the dog. Am. J. Physiol. 232: 1335 (1977).

18. Sladen. A.. Laver. M. B. and Pontoppidan. H.: Pulmonary complications and water retention in prolonged mechanical ventilation. N. Engl. J. Med.. 273 . $637(1965)$

19. Speidel. B. D.. and Dunn. P. M.: Effect of continuous positive airway pressure on breathing patterns of infants with respiratory distress syndrome. Lancet. $I$ $302(1975)$

20. Steel, R. (i. D.. and Torrie. J. H.: Principles and Procedures of Statistics. p. III (Mc(iraw-Hill Book (ompany. New York. 1980).

21. Winer. B. J.: Statistical Principles in Experimental Design. p. 261 (Mc(iraw-Hil Book (ompany. New York. 1971).

22. Yu. V. Y. H.. Rolfe. P.: Eflects of continuous positive airu ay pressure hreathing on cardiorespiralory function in infants with respiratory distress syndrome. Acta Paediatr. Scand., o6: 59 (1977).

23. The authors gratefully acknowledge the assistance of Mimi Zeiger in preparation of this manuscript.

24. Requests for reprints should be addressed to: Dr. J. B. Norton. Department of Pediatrics. University of Arkansas for Medical Sciences, 4.301 W. Markham. Little Rocks, AR 72205 (USA).

25. Received for publication November 12.1979

26. Accepted for publication January 21. 1980. 